International Journal of Automotive and Mechanical Engineering ISSN: 2229-8649 (Print); ISSN: 2180-1606 (Online)

Volume 15, Issue 2 pp. 5251-5272 June 2018

(C) Universiti Malaysia Pahang, Malaysia

DOI: https://doi.org/10.15282/ijame.15.2.2018.8.0405

\title{
Fatigue Feature Clustering of Modified Automotive Strain Signals for Saving Testing Time
}

\author{
Husaini" ${ }^{*}$ T. E. Putra and N. Ali \\ Laboratory of Computational Mechanics, \\ Department of Mechanical Engineering - Syiah Kuala University \\ Darussalam, Banda Aceh 23111, Indonesia \\ *Email: husainiftm@unsyiah.ac.id \\ Phone: +62811685495
}

\begin{abstract}
This paper discusses on the clustering of damaging fragments from a fatigue data editing leading to fatigue damage using the fuzzy $C$-means. In this work, strain signals were measured from an automotive coil spring which involved vehicle movements on three types of road surfaces at different speeds. Next, the extractions of higher amplitude cycle utilising the wavelet transform were conducted. From the results, it was obtained that the transformation was able to shorten the strain signal time up to $81.5 \%$ removing $81.5 \%$ of lower amplitude cycles, which these cycles theoretically contribute to minimum fatigue damage. Therefore, retaining of fatigue damage by more than $90.4 \%$ was obtained. Furthermore, the resulted fragments from the extraction processes had been clustered utilising the fuzzy $C$-means, providing a significant coefficient of determination, reaching 0.9036 . The testing time was successfully decreased up to $81.4 \%$ using the edited strain signals. In conclusion, the technique could be successfully used to shorten a strain signal without changing the main history.
\end{abstract}

Keywords: Vibration; Morlet wavelet, fuzzy $C$-means; life.

\section{INTRODUCTION}

Many automotive components can be associated with failure due to fatigue during their operations. The vehicle body sustains the weight of the engine and the passengers, while the vehicle body itself is sustained by a suspension system on each tire [1]. The weight of the vehicle body and the loads it carries provide the initial compressive forces to the suspension system components. The compressive forces increase if the vehicle goes through uneven road surfaces at a higher speed. After experiencing shocks, there is a probability of a high displacement of tires from the main car body and transmission of vibrations to the car.

In the automotive systems, the vibrations generated are often absorbed by vehicular components like tires, seat springs and coil springs present in the suspension system. While the tires and the seat springs absorb some vibrations, the coil springs are mainly responsible for absorbing vibrations and ensuring a safe and convenient driving experience. Under such circumstances the coil springs show forced vibrations. High shocks affect the coil springs significantly, more than the other components in the car. Hence, the coil springs are seen to play an important role in the car failure as they have to tolerate the many vibrations due to the roughness of the road surfaces; which 
increases the fatigue-dependent mechanical failure, as the car component gets exposed to cyclic loads.

In many of the applications, the fatigue random time history is very long and contains a mix of high and low amplitude cycles. With respect to this problem, it is seen that the fatigue damage due to low amplitude cycles is very small. Hence, the automotive engineers are striving to completely remove low amplitude cycles from initial histories and accelerate fatigue tests for saving time and money [2,3]. This technique is called fatigue data editing (FDE).

The trend of the FDE technique appeared when Oh [4] utilizing the discrete wavelet transform (DWT) to de-noise and eliminate spikes of strain signals. Another DWT-based FDE had also been created by Abdullah et al. [5]. Recently, Putra et al. [6,7] developed a FDE algorithm based on the continuous wavelet transform (CWT) giving a significant result in terms of saving fatigue testing. The question then arose as to how accurate the algorithms are in shortening a strain signal. Thus, to answer the question, this study aims to cluster the lower and higher amplitude fragments resulted from an extraction process using the fuzzy $C$-means (FCM).

\section{EXPERIMENTAL SETUP}

\section{Strain Signal Measurement}

In this study, the research acquired the strain signals after placing a strain gage in a critical location in the coil spring of the car and then driving the vehicle on the public road surfaces. The finite element analysis [6,7] was used for detecting the high-stress area in the component and the strain gage was installed in that area. The SAE5160 carbon steel was selected as the material for the simulation, which is generally applied in many automotive industries for the fabrication of the coil springs [8]. Table 1 describes the material properties.

Table 1. Mechanical properties of the SAE5160 carbon steel [9].

\begin{tabular}{lc}
\hline \multicolumn{1}{c}{ Properties } & Values \\
\hline Ultimate tensile strength (MPa) & 1,584 \\
Material modulus of elasticity (GPa) & 207 \\
Yield strength (MPa) & 1,487 \\
Fatigue strength coefficient (MPa) & 2,063 \\
Fatigue strength exponent & -0.08 \\
Fatigue ductility exponent & -1.05 \\
Fatigue ductility coefficient & 9.56 \\
Cyclic strain hardening exponent & 0.05 \\
Cyclic strength coefficient (MPa) & 1,940 \\
Poisson ratio & 0.27 \\
\hline
\end{tabular}

The strain gage was linked to a data logging device with the help of a connector. The fatigue data logger was utilized for recording the strain signals which were acquired by the sensor. In an earlier study, Ilic [10] mentioned that while determining the expected frequency range of the torque signal, the sampling frequency value for acquiring strain signals must be greater than $400 \mathrm{~Hz}$. This prevents the loss of the signal's essential components. If the collection rate is higher than $500 \mathrm{~Hz}$, the upper 
frequency range value can be increased, since it helps in acquiring the high-frequency load cycles and smaller amplitudes. Furthermore, collecting the load histories at the frequencies around $500 \mathrm{~Hz}$ helps in detecting and capturing the damaging load cycles as a majority of the load cycles which occur at the frequency values greater than $50 \mathrm{~Hz}$ show a small amplitude that is lesser than their endurance limits (i.e., non-damaging load cycles) [11], and the selection of $500 \mathrm{~Hz}$ was seemingly suitable for the on-site strain signal collection. After installing the equipment, the vehicle was then driven on different road surfaces like the highway, the urban and the rural roads at the speed ranging between of $70-80 \mathrm{~km} / \mathrm{h}, 30-40 \mathrm{~km} / \mathrm{h}$ and $20-40 \mathrm{~km} / \mathrm{h}$, respectively. Figure 1 shows the strain gage installation.

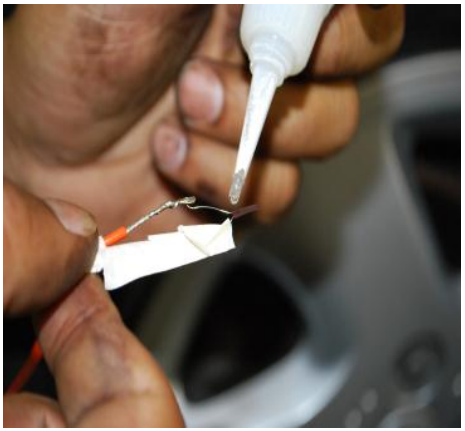

(a)

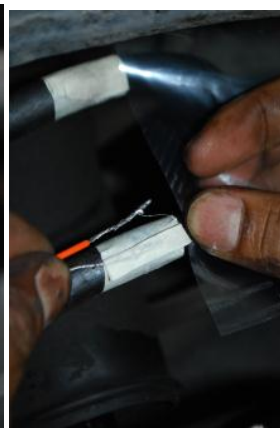

(b)

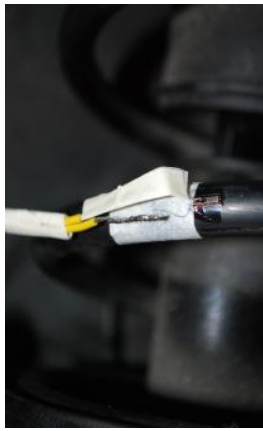

(c)

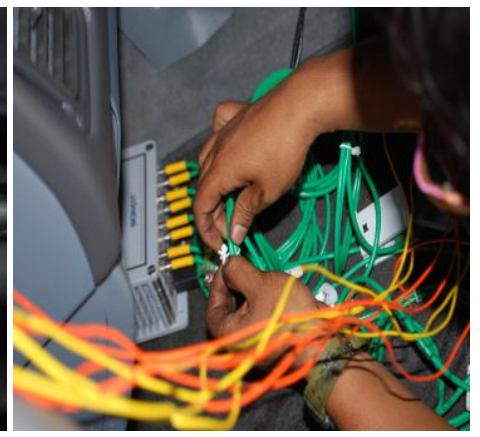

(d)

Figure 1. The strain gage installation: (a) applying adhesive to the strain gage, (b) placing strain gage on the component surface, (c) view of the installed strain gage, and

(d) connecting strain gage to the data acquisition.

\section{Fatigue damage}

Accurate assessment of fatigue life can be carried out by the strain-life approach as it considers the plastic-forming events existing in the local area. This strain-life approach is generally used for ductile materials; as a low cycle fatigue of the smaller components [12-14] (within $10^{3}$ cycles) [15-17], do not need extensive crack observations or high operational costs for their failure. Fatigue behavior of engineering materials is very sensitive to mean stress, geometric design, surface effect, metallic variables and environment [18]. Mean stress, however, is an important factor in the fatigue analysis $[14,19]$, and it is seen to affect the low and the high cycle fatigue regimes [20,21]. Thus, mostly developed fatigue life assessments consider the mean stress effects on the fatigue properties.

The applications which are based on the mean stress effects can be investigated using a type of the strain-life model, i.e., the Morrow model [22], which is expressed in Eq. (1).

$$
\varepsilon=\sigma_{f}^{\prime}-\sigma_{\text {mean }} / E\left(2 N_{f}\right)^{b}+\varepsilon_{f}^{\prime}\left(2 N_{f}\right)^{c}
$$

where $\varepsilon$ is the strain amplitude, $\sigma_{f}^{\prime}$ is the fatigue strength coefficient, $\sigma_{\text {mean }}$ is the mean stress amplitude, $E$ is the material modulus of elasticity, $N_{f}$ is the number of cycles to failure for a particular stress range and mean, $b$ is the fatigue strength exponent, $\varepsilon_{f}^{\prime}$ is the fatigue ductile coefficient and $c$ is the fatigue ductile exponent. Furthermore, Smith, 
Watson and Topper suggested another mean stress correction model, known as the SWT parameter [23], which is defined mathematically as in Eq. (2).

$$
\sigma_{\max } \varepsilon=\sigma_{f}^{\prime}{ }^{2} / E\left(2 N_{f}\right)^{2 b}+\sigma_{f}^{\prime} \varepsilon_{f}^{\prime}\left(2 N_{f}\right)^{b+c}
$$

where $\sigma_{\max }$ is the maximum stress amplitude. Cumulative fatigue damage is determined by the addition of normal and shear energy for each peak-valley in each loading. Thus, it is influenced by variable amplitude and frequency cycles. The fatigue damage for each loading cycle $D_{i}$ is defined as in Eq. (3).

$$
D_{i}=1 / N_{f}
$$

Thereafter, the Palmgren-Miner linear cumulative fatigue damage rule [24,25] is applied for estimating the cumulative fatigue damage $D$ of the loading, which is defined as Eq. (4).

$$
D=\sum\left(n_{i} / N_{f}\right)
$$

where $n_{i}$ is the number of applied cycles. The fatigue damage ranges between zero to one, where zero indicates no damage (i.e., infinite cycles towards failure), while one indicates a failure (i.e., one cycle towards failure) [26].

\section{Fatigue Data Editing}

The CWT can be described as a cumulative sum of the signal collected over time multiplied by a scale [27]. This is carried out for every reasonable scale, generates a lot of data and helps in determining the values of the continuous decomposition which helps in an accurate reconstruction of the signal [28]. The wavelet transform is initiated with a simple function, known as mother wavelet, and is scaled in a manner which displays the analyzed signal. The mother wavelet helps in removing the signal from the space to the scale domain for providing the local signal features.

The Morlet wavelet is an advanced form of the mother wavelets involving the CWT [29], and is described in Eq. (5) [30,31]:

$$
\psi_{(t)}=1 / \pi^{1 / 4} e^{i 2 \pi f_{0} t} e^{-t^{2} / 2}
$$

where $t$ is the time and $f_{0}$ is the central frequency of the mother wavelet $\Psi$. The wavelet decomposition estimates the resemblance index, or the coefficient [32], which results due to the signal regression which is generated at various scales within the wavelet. The coefficient establishes a correlation between the analyzed part of a signal and the wavelet. Higher the coefficient, stronger is the resemblance, while a low coefficient indicates a weaker resemblance [28]. The wavelet coefficient WC of the CWT is described with the integral as in Eq. (6) [33].

$$
W C_{(p, q)}=1 / \sqrt{p} \int_{-\infty}^{+\infty} F_{\mathrm{j}(t)} \psi(t-q / p) d t
$$


where $q$ is the time shifting, $p$ is the scale index and $F_{\mathrm{j}}$ is the signal amplitude. The mother wavelet is square integral or, equivalently, has finite energy. Hence, a wavelet coefficient provides an energy distribution display for a specific time and frequency by squaring the coefficients at every time interval. The wavelet-based signal internal energy $\bar{e}$ is described by Eq. (7) [34].

$\bar{e}_{(p, q)}=\int_{-\infty}^{+\infty}\left|W C_{(t)}\right|^{2} d t$

The energy was then utilized to identify the amplitude changing in a strain signal. A lower scale in the wavelet coefficient presents a higher frequency and has small strain amplitude, meaning this cycle has a lower energy, which is indicate a minimum or no potential for fatigue damage. A larger scale in the wavelet coefficient presents a lower frequency and higher strain amplitude, showing this cycle has a higher energy causing fatigue damage [35].

Identification of the peak-valley could be utilized to slice a strain signal so that each fragment contains a number of certain peaks and valleys. This is especially useful for fatigue signals, since characteristics of the peak-valley are dominant in the rainflow method utilized for determining the number of cycles [3]. Thus, an algorithm was created to generate a new magnitude taking the points of peak and valley only by comparing the magnitude values.

Moreover, the fatigue damaging fragments in a strain signal were extracted, depending on their high energy distribution, which resulted in the fragments that contributed towards fatigue damage. Energy gate value (EGV), an energy spectrum variable parameter, was applied for determining the minimal magnitude level which could be maintained in a wavelet domain. If the maximal wavelet-based energy is donated as $\bar{e}_{\max }$, the EGV can be represented in Eq. (8).

$$
E G V=\bar{e}_{\max }^{h}
$$

where $h$ is the multiplicative factor that can be any positive number. Energies that were higher than the EGV should be retained based on their positions on the time axis to generate fragments which were contributed to cumulative fatigue damage. Instead, all energies that were less than the EGV were eliminated. Since fragments which were consist of a low magnitude denote fragments with low fatigue damage, the fatigue characteristic extraction was predicted to be able to retain the majority of fatigue damage in the strain signal.

Figure 2 presents the concept of fragment identification. The selection of a maintained fragment was based on energy loss, which occurs when the chosen fragment was at the beginning of the swing so that it ends. The starting point of the fragment was the valley point if the previous peak was higher than the peak after the valley point. Meanwhile, the endpoint of the fragment was assumed the valley point if the peak after the point was higher than the peak before the point. Thus, the identification of the extracted fragment was conducted by finding the inverse of two points (on each peak). Once all the extracted fragments were identified, the energy time history was then scraped to eliminate lower energy (less than the EGV) contained in the range of the initial time history. The positions of the extracted fragments were then transferred to the initial strain signal in the time domain for the elimination of fragments that were not 
needed. The fragments to be eliminated were then sliced from the initial strain signal based on the position of the fragments.

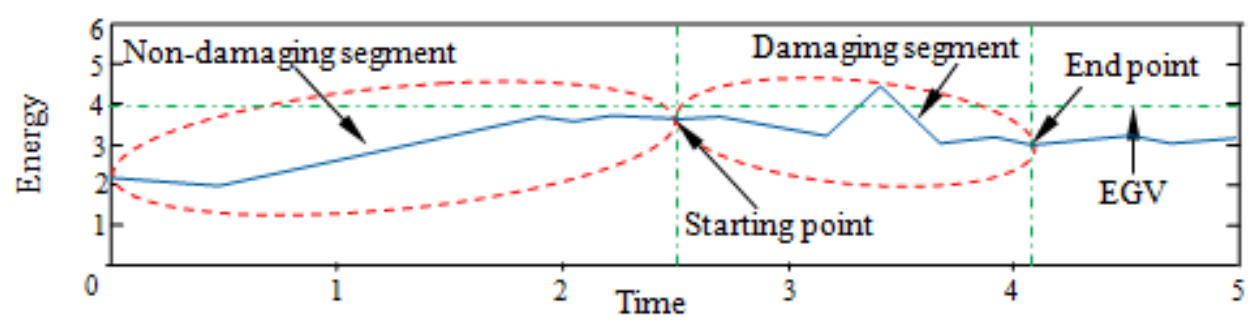

Figure 2. Concept of the fragment identification.

To get the optimum EGV, the retained fragments were then attached with each other to produce a shorter strain signal, in comparison to the initial strain signal, but had equivalent behavior to the initial strain signal. A different EGV resulted in a differently modified strain signal. After increasing the EGV, a shorter strain signal was generated since more magnitude cycles were under the higher EGV. Therefore, resulting strain signal was shorter when more fragments were eliminated. However, the edited strain signal at a higher EGV gave real decline in retaining the initial characteristics of the strain signal. If the resulted modified strain signal did not meet the criteria, the EGV was decreased to obtain the required modified strain signal. After reducing the EGV, the characteristics of the modified strain signal increased and were even equal to the initial characteristics.

\section{Fatigue Feature Clustering}

Clustering is the classification of data into different groups. In other words, clustering maps a dataset into smaller clusters such that the data in all the clusters share several common characteristics according to the defined distance measure [36]. One of the keys in clustering is the function used to measure the similarity between two data being compared. These data could be in various forms, including raw values of equal or unequal lengths [37].

The method utilized for clustering in the current study was FCM [38], since it gives a good result based on the distance to the cluster centre, also known as the centroid of each data that is closer. The objective function $J$ of the FCM is described by Eq. (9).

$$
J_{(U, v)}=\sum_{k=1}^{n} \sum_{i=1}^{C} U_{i k}^{\dot{g}}\left\|F_{\mathrm{j}_{k}}-v\right\|_{w m}^{2}
$$

where $U$ is the Fuzzy $c$-partition, $v$ is the vector of centres, $n$ is the number of data, $C$ is the number of clusters, $\dot{g}$ is the weighted exponent and $w m$ is the positive-definite weight matrix.

The FCM method can place the members of a group with the shortest distance to the centroid in a clustering. The centroid is the average of all the points in a cluster, where the coordinate is the average arithmetic for each separate dimension for all the points in a group. The other benefits of this method are its simplicity and speed in analyzing large datasets. This method began by determining the number of groups. 
Furthermore, each fragment was classified into the nearest centroid [39]. So, the fragments in each group were as close as possible and as far as possible to the other fragments in the other groups [37]. This search was accomplished by repeatedly moving the centroid to various places. The process stopped when the nearest distance was obtained [39]. This means that during the process, the desired fragment distribution was being obtained, and centralized scattering was being provided for certain fragments. This method regards fragments as having a position and distance from each other. Since the clustering method is new in the fatigue field, the results of the current study are expected to provide new knowledge on the applicability of the FCM in fatigue research.

\section{Fatigue Test}

The reason to conduct variable amplitude loading (VAL) fatigue tests in the current study was to show the time reduced utilizing the edited strain signals. The VAL fatigue tests were conducted as it was impossible to assess the fatigue lives of the complex loadings using any hypothesis [40-43]. A VAL fatigue test is principally carried out like constant amplitude loading (CAL) fatigue test at different loading levels, with a given load being continuously repeated until failure is obtained. The only difference is that in cases of CAL, the amplitude (or range) remains unchanged. Thus, VAL fatigue tests are more complicated, and often, more time-consuming and expensive than CAL fatigue tests [44].

All the fatigue testing samples were designed as per ASTM E606-92 [45], norms as described in Figure 3. The geometry and the dimensions of the samples and the appropriate grips used in the fatigue testing device have been specified. The samples were fabricated with the help of the computer numerical controls and grinding machines. Thereafter, they were mechanically polished [46] for ensuring the removal of the machining marks during testing. As the fatigue cracks develop on irregular road surfaces, the sample condition plays a vital role during the fatigue testing. It can decrease the stress concentration which further prevents the initiation of cracks at those specific sites. All the tests were conducted at a room temperature of $20{ }^{\circ} \mathrm{C}$ [45].
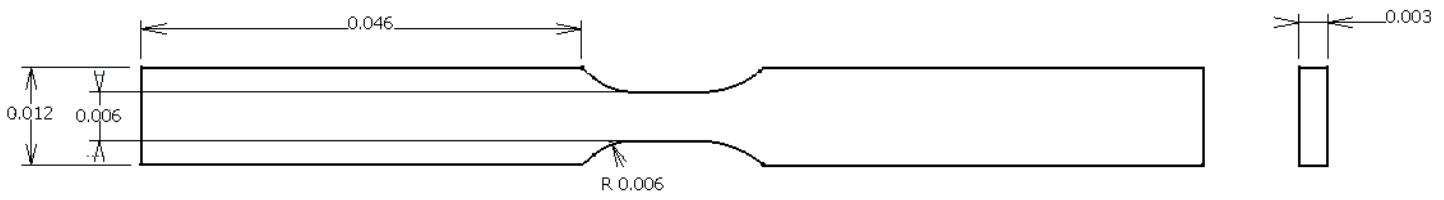

(a)

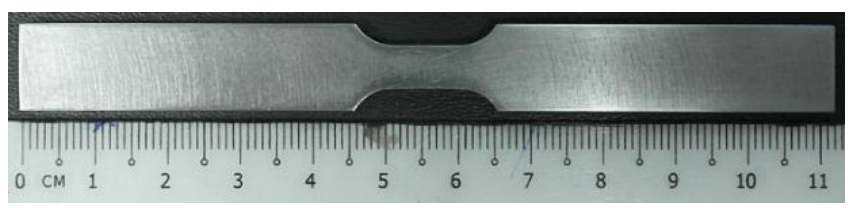

(b)

Figure 3. Fatigue test (a) dimensions in mm and; (b) sample.

The initial and edited strain signals have been converted into stresses with the help of the Ramberg-Osgood equation [47], described in Eq. (10). 


$$
\varepsilon=\sigma / E+K^{\prime}(\sigma / E)^{n}
$$

where $\sigma$ is the stress amplitude, $K^{\prime}$ is the cyclic strength coefficient and $n^{\prime}$ is the cyclic strain hardening exponent. Thereafter, the stresses have been converted into loads which were used as an input value in the fatigue testing device which help of the expression of Eq. (11).

$$
\sigma=P / A_{0}
$$

where $P$ is the applied force and $A_{0}$ is the initial unloaded cross-sectional area. The reversed VAL fatigue tests were carried out, using a $100 \mathrm{~Hz}$ frequency value [16,48]. The researchers did not note any effect of a high frequency on the crack initiation $[21,48]$. The effect of the frequency value on the fatigue test result is generally low for frequencies up to $1,000 \mathrm{~Hz}[16]$.

\section{RESULTS AND DISCUSSION}

\section{Strain Signal Characteristics}

The strain signals generated by the strain gage were considered a VAL as the component experienced multiple amplitudes. 30-second long signals for each of the 15,000 data points were recorded and described in Figure 4, and they were said to be sufficient for studying the fatigue-based strain signal behavior and evaluating fatigue life. The urban road gave the lowest amplitude range, which was between $57.6 \mu \varepsilon$ and $190.6 \mu \varepsilon$. A higher amplitude range could be found in the highway road, distributed between $-47.4 \mu \varepsilon$ and $96.6 \mu \varepsilon$. However, the rural road had the highest amplitude range, which was between $-128.5 \mu \varepsilon$ and $182.3 \mu \varepsilon$. The rural road gave higher amplitudes than other roads because its surface was rough. Differences of the amplitude range could be linked to the road surface profiles.

As a structure consist of few loads at the single stress or strain levels, the fatigue damage can be estimated based on the number of cycles towards failure. Based on the results, the number of cycles for the highway, the urban and the rural strain signals was $3,023,3,020$ and 2,993, respectively. Since the rural strain signal provided the highest strain amplitude contributing to the highest stress at the coil spring, the strain signal was found to have the highest fatigue damage, which was $7.79 \times 10^{-5}$ and $9.01 \times 10^{-5}$ damage per block for the Morrow and SWT models, respectively. The highway strain signal showed the fatigue damage of $3.97 \times 10^{-8}$ and $8.77 \times 10^{-8}$ damage per block, while the urban strain signal showed a fatigue damage of $1.72 \times 10^{-7}$ and $5.67 \times 10^{-7}$ damage per block. Findings showed that the rural road caused stronger vibrations to the coil spring because it has a rough surface; meanwhile, the highway and urban roads provided lower vibrations because the roads were smooth. Damage due to fatigue increases with the vibrations subjected to a component leading to fracture.

Furthermore, since the rural road provided the highest fatigue damage, the strain signal also gave the shortest fatigue life, which was only 12,840 and 11,096 reversals of blocks for the Morrow and SWT models, respectively. The fatigue life for the highway strain signal was $25,184,000$ and 11,400,000 reversals of blocks, and the fatigue life for the urban strain signal was 5,828,000 and 1,764,400 reversals of blocks. It indicated that the rural road also gave the shortest useful life compared to the highway and urban 
roads, since the road had a rough surface. Some of the non-stationary vibrations include bumps, holes, turns, speed changes, accelerations, brakes and uneven tar patch on the road. These factors lead to high strains and cause high fatigue damage.

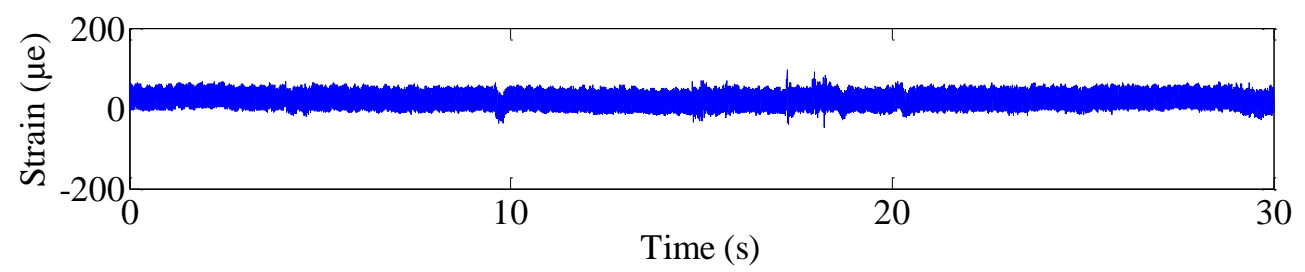

(a)

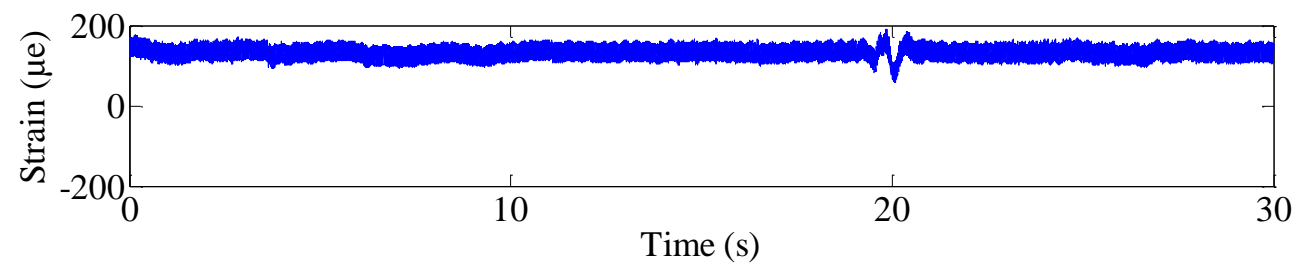

(b)

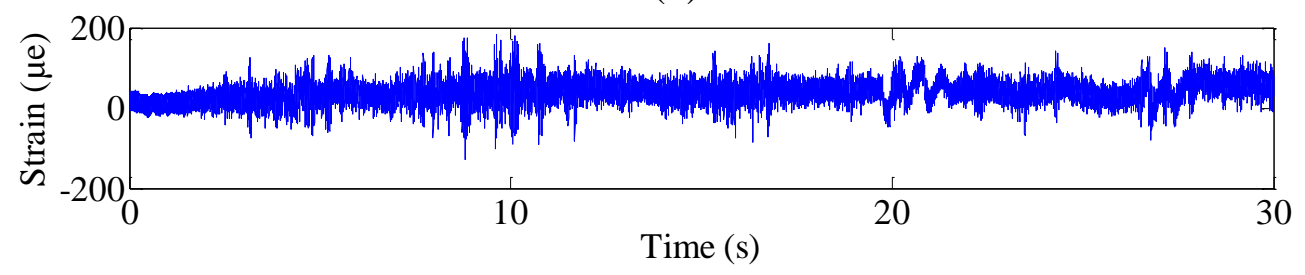

(c)

Figure 4. Time history strain signals from (a) highway, (b) urban, (c) rural.

\section{Modified Strain Signals}

The strain signals were extracted for obtaining the damaging fragments, with the help of the wavelet-based FDE method. In the wavelet coefficients shown in Figure 5, the matrix row ( $x$-axis) presents the time parameter, while the matrix column $(y$-axis) presents the scale parameter, which is inversely related to the frequency. The wavelet coefficients show how the energy of the strain signals was divided in the time-frequency domain [35]. The energy contained in a particular scale and position was denoted as a wavelet energy density function. The energy spectrum was plotted and the content gave important information about the pattern of the random strain signals. In Figure 6, the surface of the scalogram provides the position of the dominant energy. Comparing Figure 6 , the rural strain signal provided higher amplitude. This was in line with the strain amplitudes in Figure 4, since energy fed to a strain signal usually originates from strain amplitude variations. 


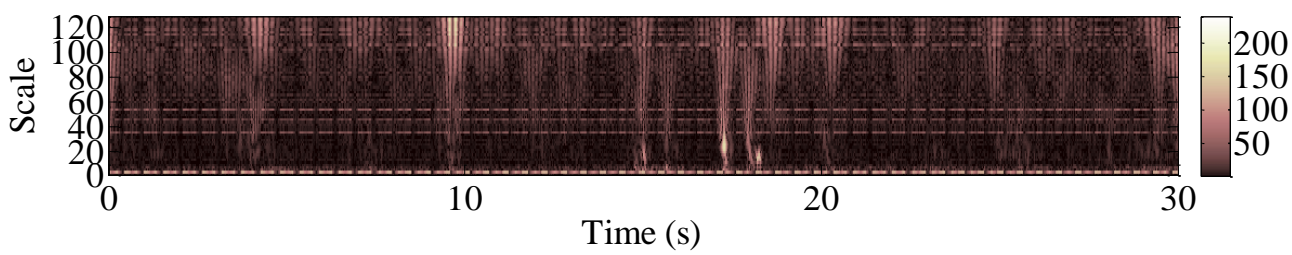

(a)

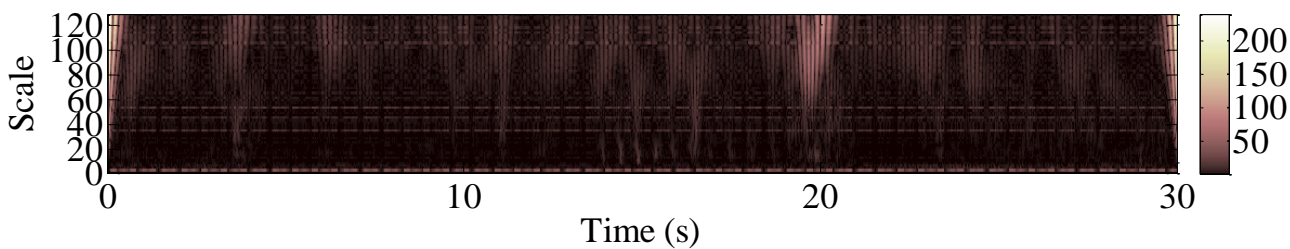

(b)

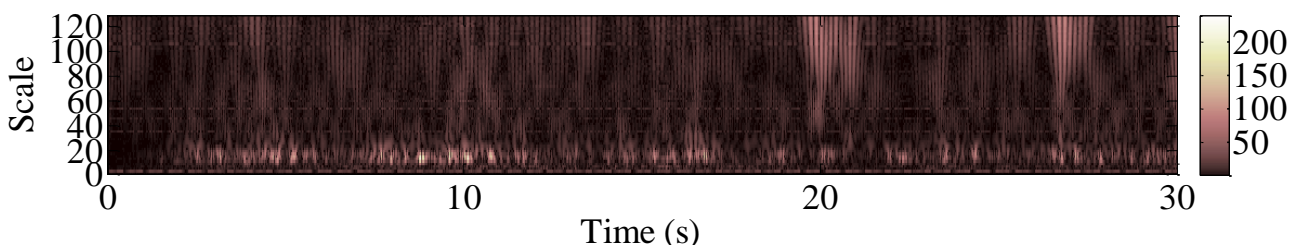

(c)

Figure 5. Wavelet coefficients of (a) highway, (b) urban and; (c) rural.

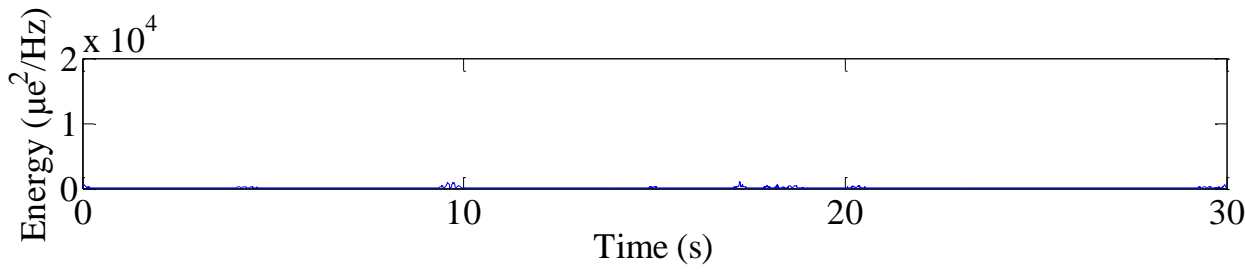

(a)

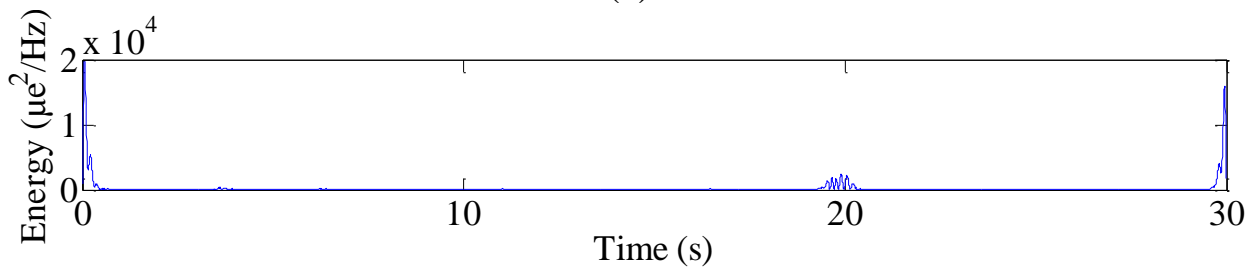

(b)

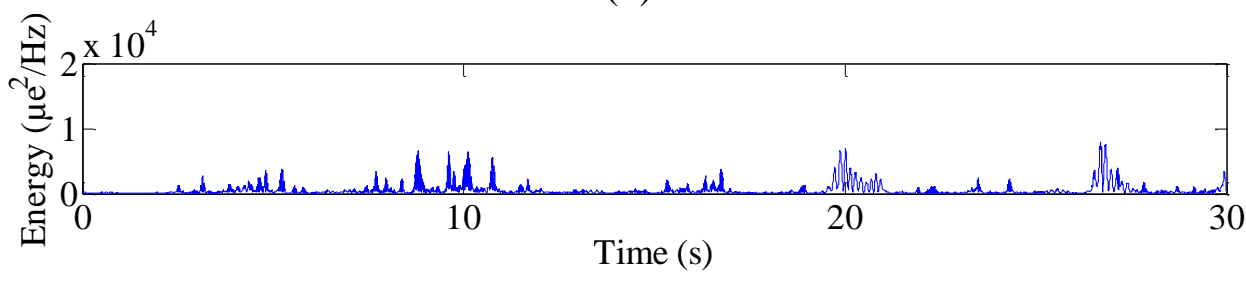

(c)

Figure 6. Energy distributions in (a) highway, (b) urban and; (c) rural.

Equation (8) was used for detecting the position of the high amplitudes in the strain signals based on their magnitude spectra. This helped identify the high fatigue damaging sections in the strain signals and extracted them to generate damaging and 
non-damaging fragments. A cutting level parameter, i.e., EGV was applied for extracting the fatigue features. For the highway strain signal, the EGVs used were 128 $\mu \varepsilon^{2} / \mathrm{Hz}, 135 \mu \varepsilon^{2} / \mathrm{Hz}$ and $142 \mu \varepsilon^{2} / \mathrm{Hz}$. Furthermore, the urban strain signal was extracted at $20 \mu \varepsilon^{2} / \mathrm{Hz}, 32 \mu \varepsilon^{2} / \mathrm{Hz}$ and $42 \mu \varepsilon^{2} / \mathrm{Hz}$. The last one, $2,404 \mu \varepsilon^{2} / \mathrm{Hz}, 2,458 \mu \varepsilon^{2} / \mathrm{Hz}$ and $2,513 \mu \varepsilon^{2} / \mathrm{Hz}$ of EGVs were applied to the rural strain signal. The EGVs were selected as a majority of the energy values were lower than the EGVs. The energy values higher than the EGV were kept, whereas the energy values lesser than the EGV magnitudes were eliminated from the strain signals. Low energy fragments were considered as nondamaging, and their removal did not alter the damage relevance or the primary strain signal properties. After extracting all the strain signals, the high-energy retained fragments were obtained, as shown in Figures 7-9.

Furthermore, depending on the time positions of the retained high energy fragments and referring to the strain signals in Figure 4, maintained fragments were obtained. The retained fragments were damaging fragments because they had slightly more energies than the EGV. Meanwhile, the eliminated fragments were non-damaging fragments since the energy of the fragments was lower than the EGV. As the FDE method extracted the time series using the energy contents, non-uniform fragments were obtained, as described in Figures 10-12.

It was important to maintain the primary characteristics in the FDE method for ensuring that the modified strain signals and the primary strain signals were similar. Hence, the effect of the extraction at one EGV needs to be taken into consideration. This helps in certifying that the fragments that were retained fulfilled the FDE criterion of maintaining $90 \%$ fatigue damage [6,7]. Thus, the retained fragments were reattached to yield a single strain signal for validating if the extraction process was performed satisfactorily. Figures 13-15 show the differences in the length of the modified strain signals at various EGVs.

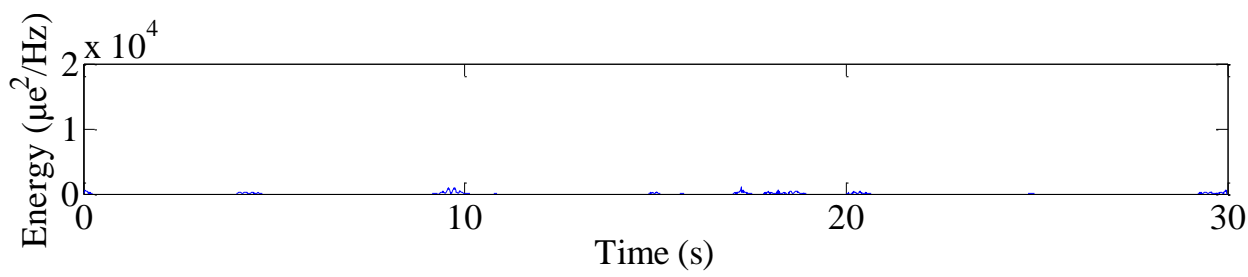

(a)

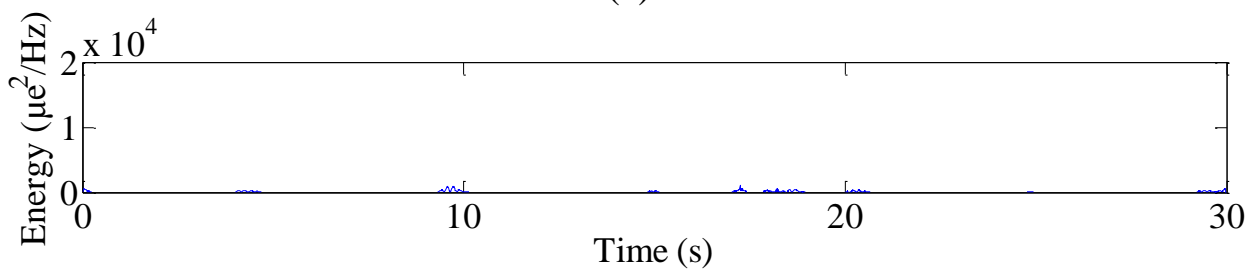

(b)

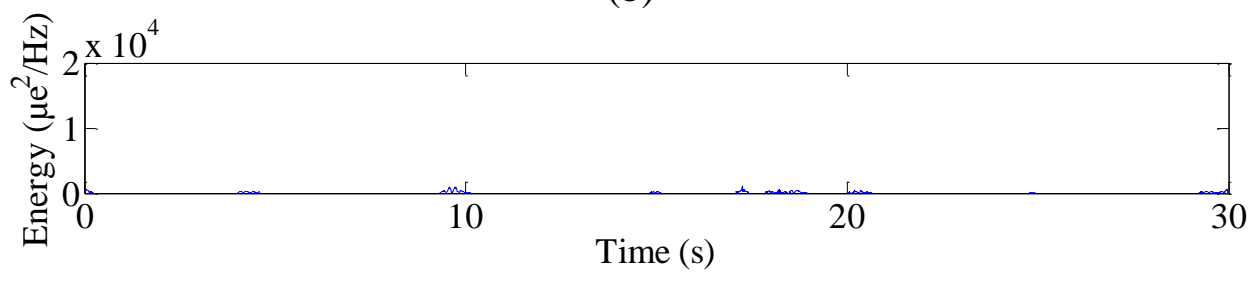

(c)

Figure 7. Maintained higher energy of the highway strain signal at (a) $128 \mu \varepsilon^{2} / \mathrm{Hz}$, (b) $135 \mu \varepsilon^{2} / \mathrm{Hz}$, (c) $142 \mu \varepsilon^{2} / \mathrm{Hz}$. 


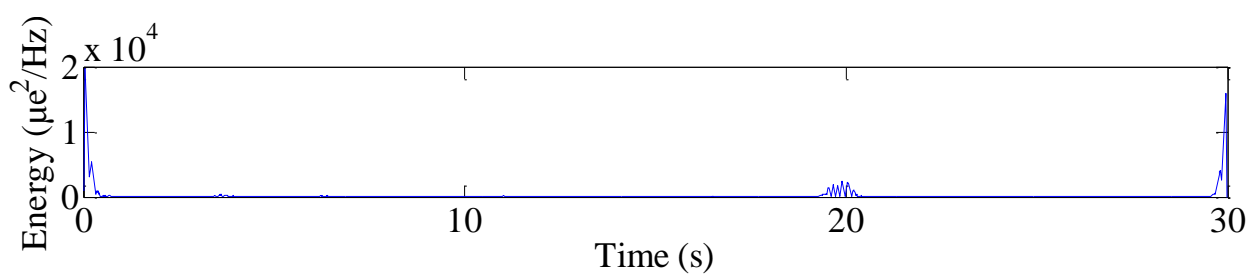

(a)

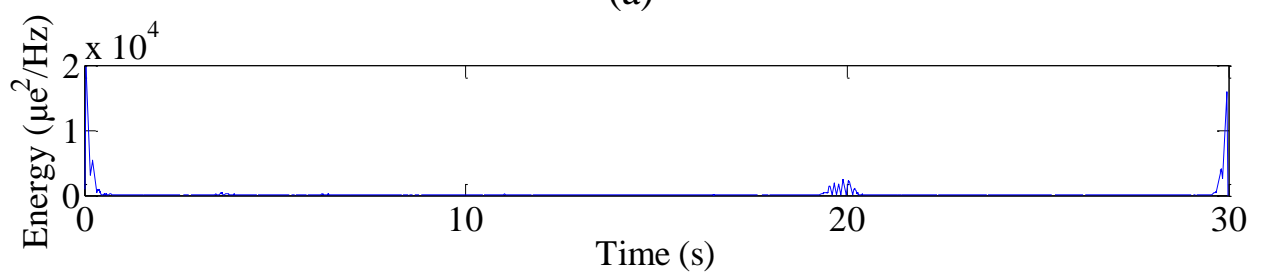

(b)

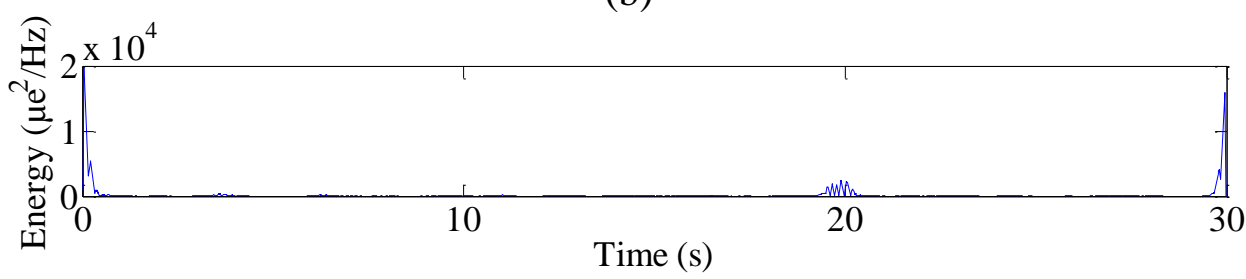

(c)

Figure 8. Maintained higher energy of the urban strain signal at (a) $20 \mu \varepsilon^{2} / \mathrm{Hz}$, (b) 32 $\mu \varepsilon^{2} / \mathrm{Hz}$, (c) $42 \mu \varepsilon^{2} / \mathrm{Hz}$.

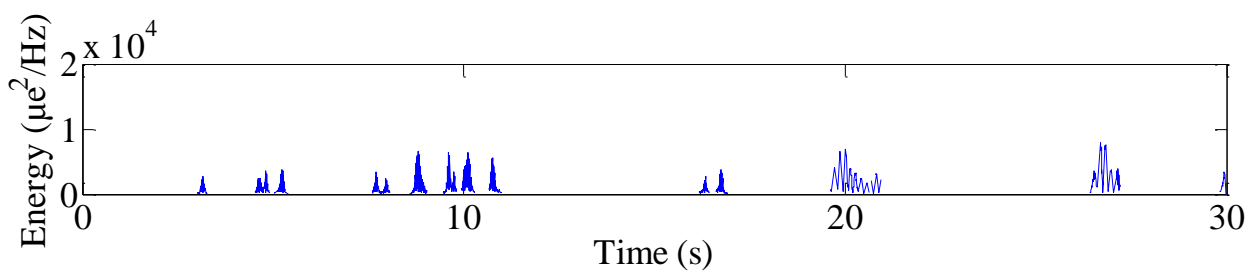

(a)

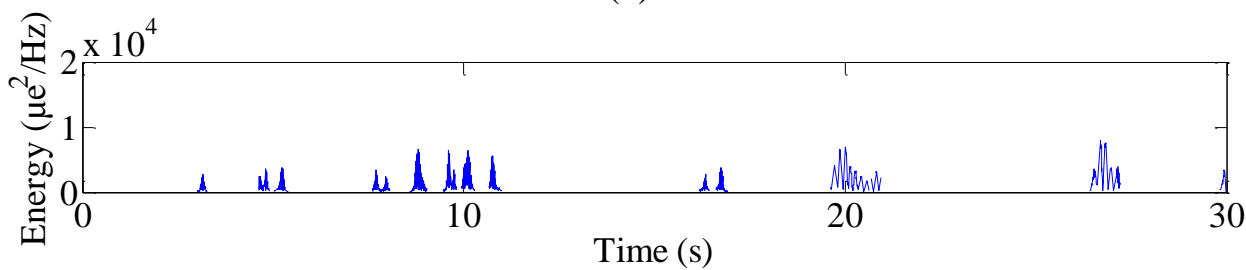

(b)

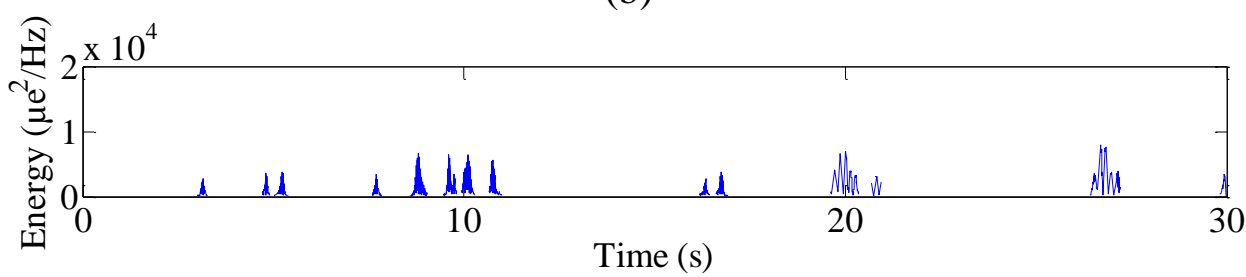

(c)

Figure 9. Maintained higher energy of the rural strain signal at (a) $2,404 \mu \varepsilon^{2} / \mathrm{Hz}$, (b) $2,458 \mu \varepsilon^{2} / \mathrm{Hz}$, (c) $2,513 \mu \varepsilon^{2} / \mathrm{Hz}$. 


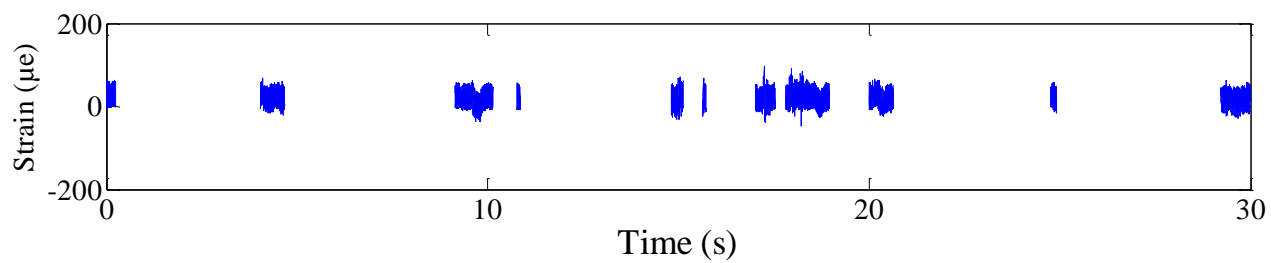

(a)

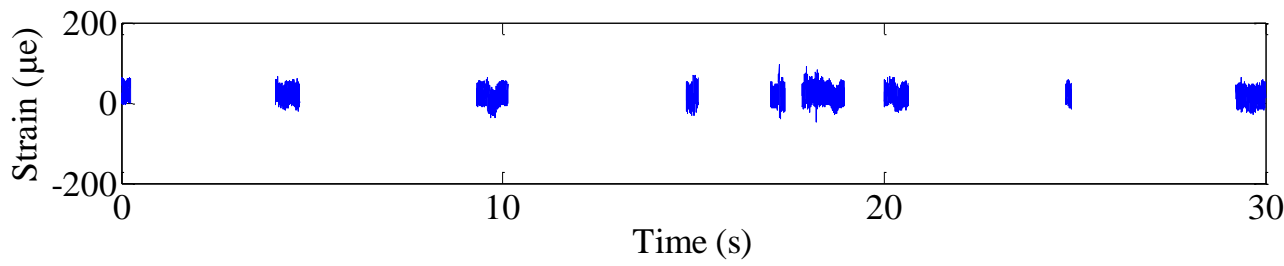

(b)

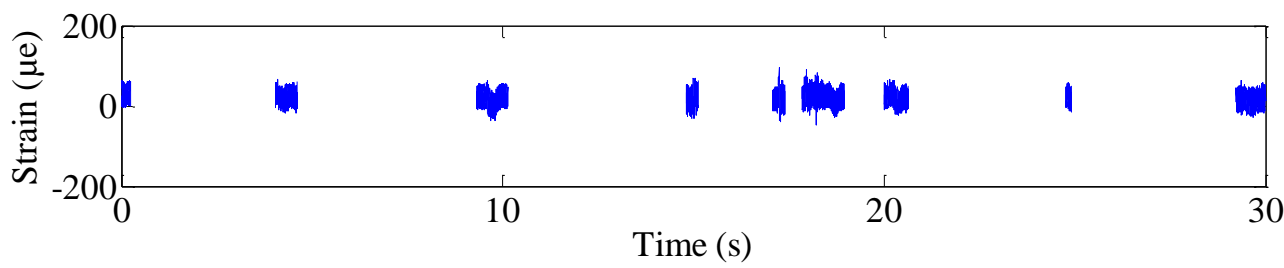

(c)

Figure 10. Maintained fragments of the highway strain signal at (a) $128 \mu \varepsilon^{2} / \mathrm{Hz}$, (b) 135 $\mu \varepsilon^{2} / \mathrm{Hz}$, (c) $142 \mu \varepsilon^{2} / \mathrm{Hz}$.

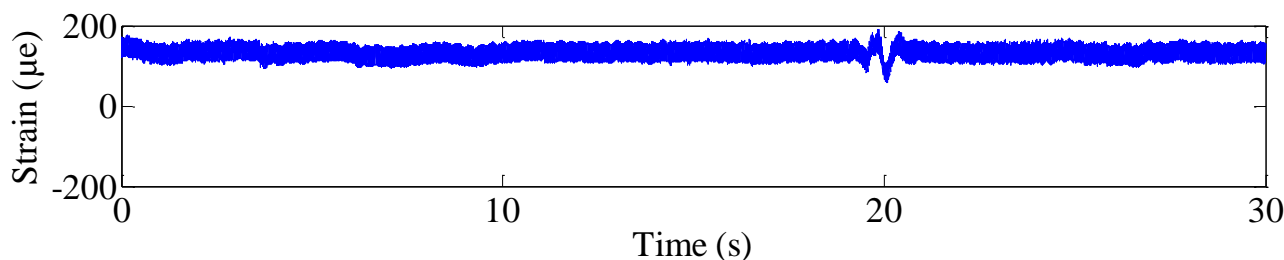

(a)

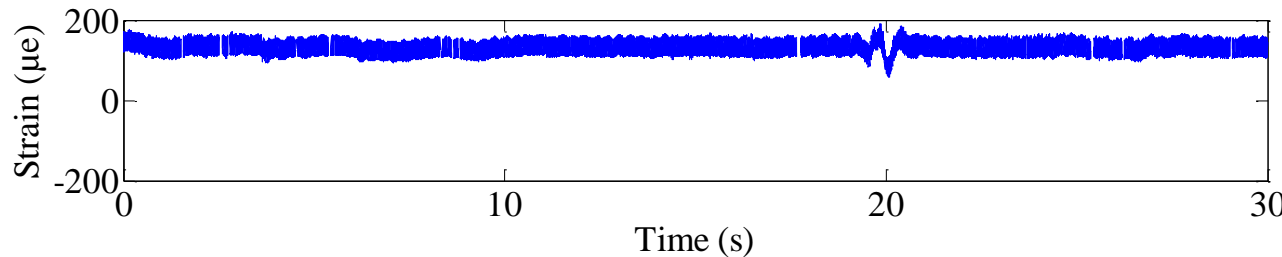

(b)

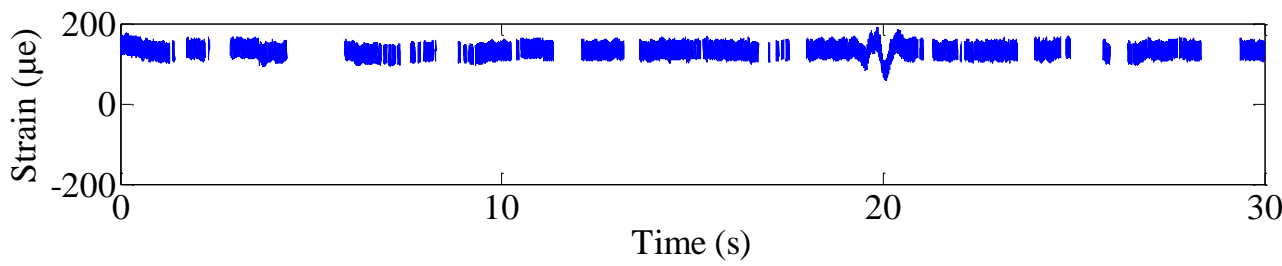

(c)

Figure 11. Maintained fragments of the urban strain signal at (a) $20 \mu \varepsilon^{2} / \mathrm{Hz}$, (b) 32 $\mu \varepsilon^{2} / \mathrm{Hz}$, (c) $42 \mu \varepsilon^{2} / \mathrm{Hz}$. 


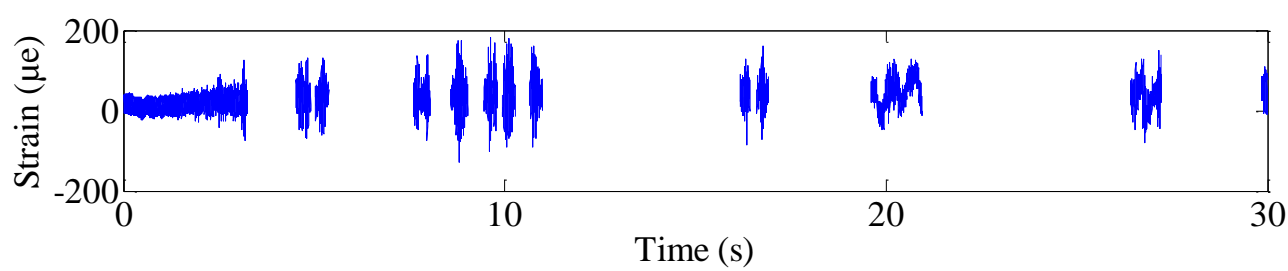

(a)

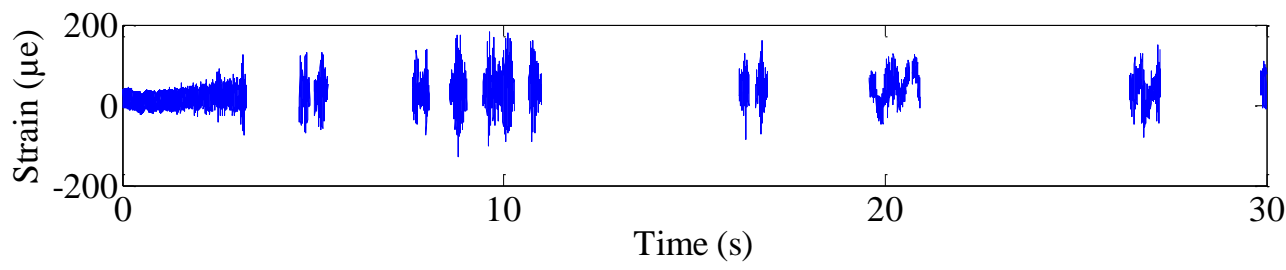

(b)

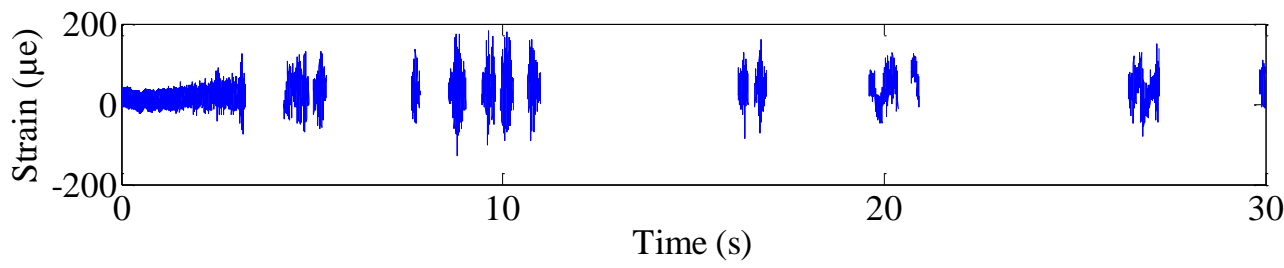

(c)

Figure 12. Maintained fragments of the rural strain signal at (a) $2,404 \mu \varepsilon^{2} / \mathrm{Hz}$, (b) 2,458 $\mu \varepsilon^{2} / \mathrm{Hz}$, (c) $2,513 \mu \varepsilon^{2} / \mathrm{Hz}$.

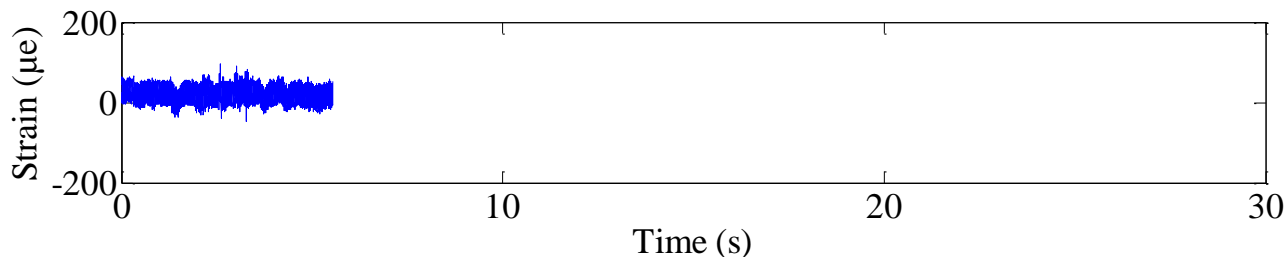

(a)

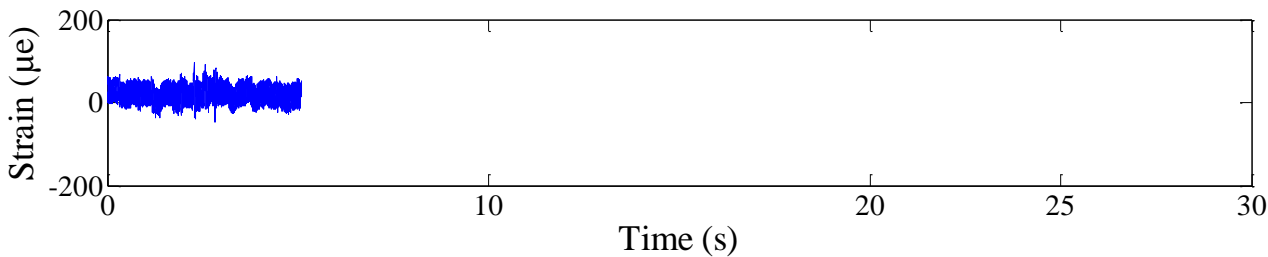

(b)

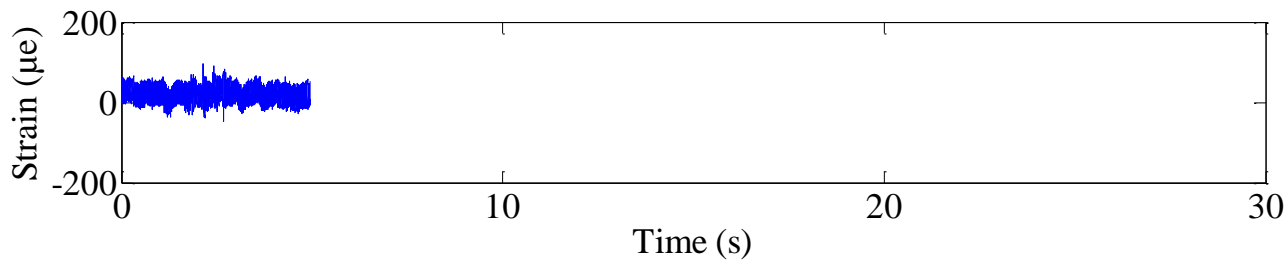

(c)

Figure 13. Modification of the highway strain signal at (a) $128 \mu \varepsilon^{2} / \mathrm{Hz}$, (b) $135 \mu \varepsilon^{2} / \mathrm{Hz}$, (c) $142 \mu \varepsilon^{2} / \mathrm{Hz}$. 


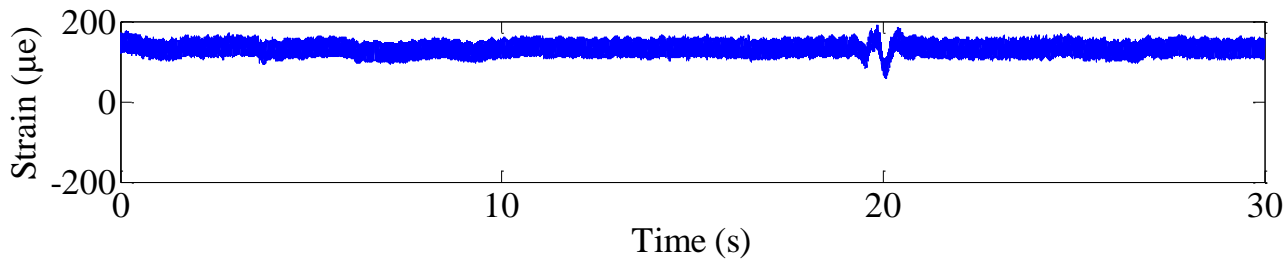

(a)

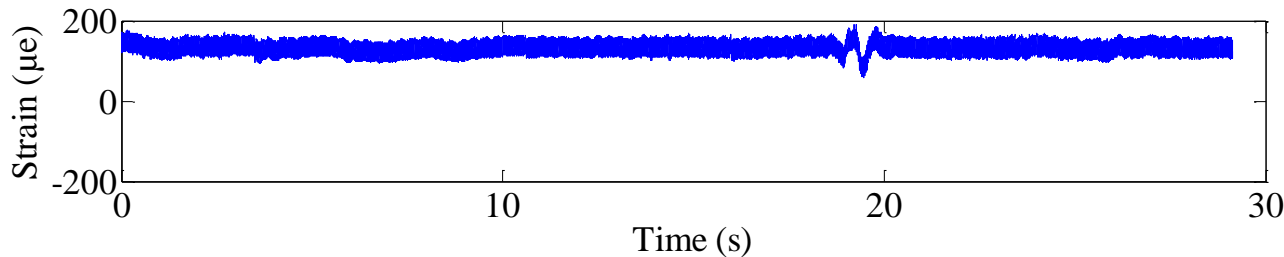

(b)

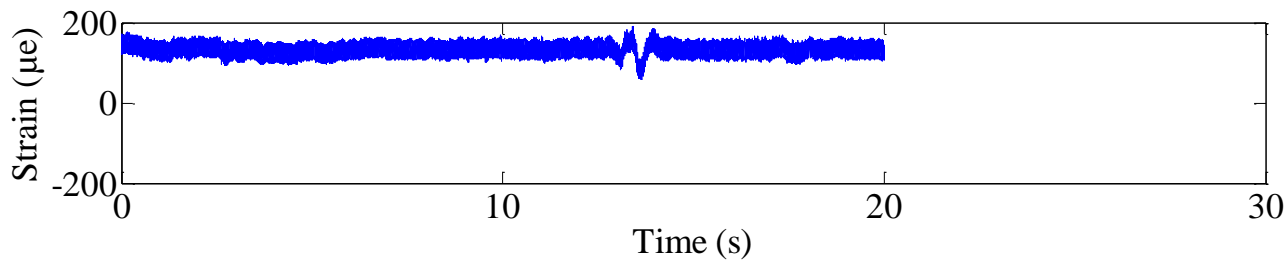

(c)

Figure 14. Modification of the urban strain signal at (a) $20 \mu \varepsilon^{2} / \mathrm{Hz}$, (b) $32 \mu \varepsilon^{2} / \mathrm{Hz}$, (c) 42 $\mu \varepsilon^{2} / \mathrm{Hz}$.

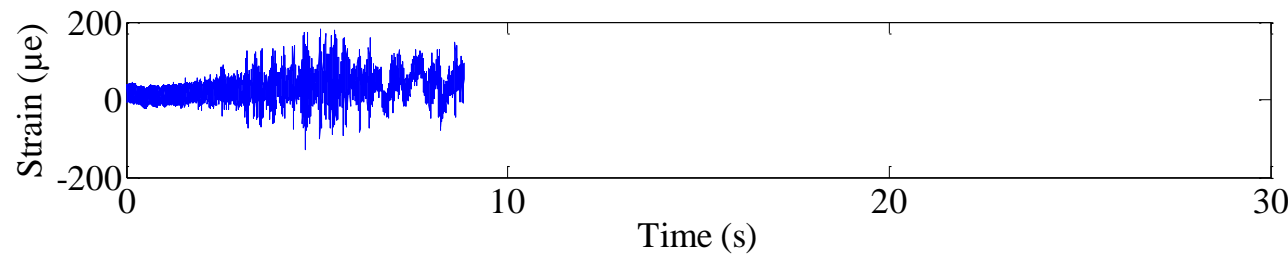

(a)

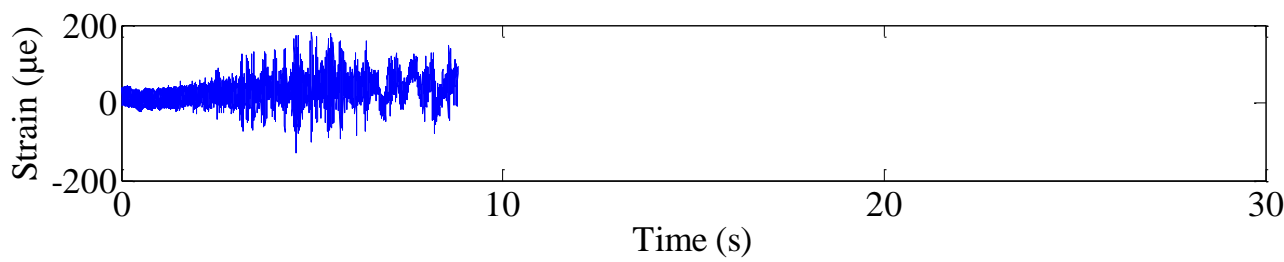

(b)

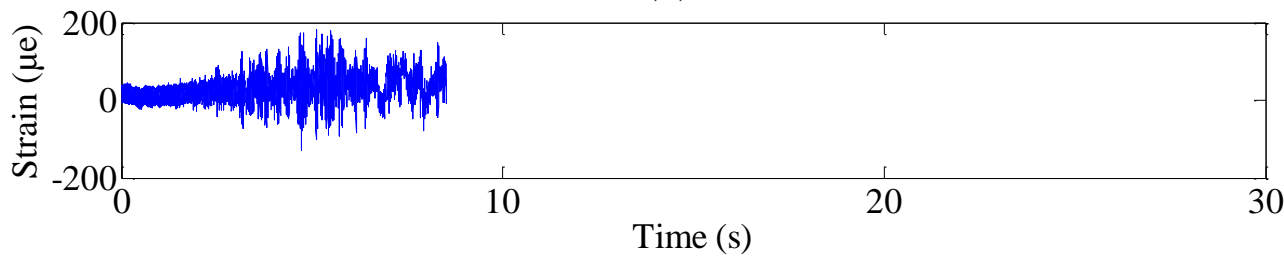

(c)

Figure 15. Modification of the rural strain signal at (a) $2,404 \mu \varepsilon^{2} / \mathrm{Hz}$, (b) $2,458 \mu \varepsilon^{2} / \mathrm{Hz}$, (c) $2,513 \mu \varepsilon^{2} / \mathrm{Hz}$. 
For the highway strain signal, the number of cycles decreased by $81.5 \%, 83 \%$ and $83.4 \%$ for the first $\left(128 \mu \varepsilon^{2} / \mathrm{Hz}\right)$, second $\left(135 \mu \varepsilon^{2} / \mathrm{H}\right)$ and third $\left(142 \mu \varepsilon^{2} / \mathrm{Hz}\right)$ extractions, respectively. There was no decrease in terms of the number of fatigue cycles for the first $\left(20 \mu \varepsilon^{2} / \mathrm{Hz}\right)$ extraction of the urban strain signal. However, a decrease of $3 \%$ and $33.4 \%$ was resulted for the second $\left(32 \mu \varepsilon^{2} / \mathrm{Hz}\right)$ and third $\left(42 \mu \varepsilon^{2} / \mathrm{Hz}\right)$ extractions. For the rural strain signal, the first $\left(2,404 \mu \varepsilon^{2} / \mathrm{Hz}\right)$, second $\left(2,458 \mu \varepsilon^{2} / \mathrm{Hz}\right)$ and third $\left(2,513 \mu \varepsilon^{2} / \mathrm{Hz}\right)$ extractions gave a decrease of $70.9 \%, 71.1 \%$ and $72 \%$. These declines indicated that the FDE process was able to remove all the strain amplitude ranges under the EGVs in the time-series signals. Thus, the signal length of the highway strain signal decreased by $81.5 \%, 83.1 \%$ and $83.5 \%$ for the first, second and third extractions. For the urban strain signal, there was no decrease in the length of the signal for the first extraction. However, there were decreases of $2.9 \%$ and $33.3 \%$ for the second and third extractions, respectively. For the rural strain signal, a decrease of 70.5 $\%, 70.6 \%$ and $71.6 \%$ was resulted for the first, second and third extractions. The decrease in the signal lengths was caused by the decrease of the number of cycles.

In terms of the fatigue damage, the Morrow model did not give any deviation in the fatigue damage for all the EGVs for the highway strain signal. The fatigue damage decrease of $9.6 \%$ was resulted for the SWT model for the first extraction. However, a decrease of $10.2 \%$ was produced for the second and third extractions. Since the EGVs of $135 \mu \varepsilon^{2} / \mathrm{Hz}$ and $142 \mu \varepsilon^{2} / \mathrm{Hz}$ could not give an eligible mission strain signal, therefore, the EGV was decreased out of necessity. Thus, based on the results, $128 \mu \varepsilon^{2} / \mathrm{Hz}$ was selected as the optimum EGV, giving a 5.5-second mission strain signal. This short strain signal gave an $81.5 \%$ reduction in length as a result of the removal of the lower energy amplitude. The number of cycles counted for the mission strain signal was 560 cycles, which was $81.5 \%$ less than the number of initial cycles. The decreasing number of cycles affected the cumulative fatigue damage. The fatigue damage for the SWT model was $7.93 \times 10^{-8}$ damage per block, which gave a reduction rate of $9.6 \%$ compared to the initial fatigue damage. The reduction in the fatigue damage indicated that this EGV did not change the strain signal behavior since the reduction was in the required range at $\pm 10 \%$ of the difference.

A similar condition could also be seen in the urban strain signal, where the Morrow model did not give any deviation in the fatigue damage for all the EGVs. A 0 $\%$ deviation in the fatigue damage was also given by the SWT model for the first extraction. Decreases of $1 \%$ and $11.7 \%$ resulted for the second and third extractions. An EGV of $32 \mu \varepsilon^{2} / \mathrm{Hz}$ was found to be the optimum EGV, containing at least $99 \%$ of the initial fatigue damage in the 29.1-second mission strain signal. An EGV of 32 $\mu \varepsilon^{2} / \mathrm{Hz}$ was considered to be the optimum because at a higher EGV (42 $\left.\mu \varepsilon^{2} / \mathrm{Hz}\right)$, the changes in fatigue damage reached more than $10 \%$, to the detriment of the initial properties of the strain signal.

For the rural strain signal, decreases were $8.3 \%$ and $8.9 \%$ for the Morrow and SWT models for the first extraction. The decreases became $8.4 \%$ and $9 \%$ for the second extraction. For the third extraction, however, the decreases became $10.3 \%$ and $11 \%$. At an EGV of $2,404 \mu \varepsilon^{2} / \mathrm{Hz}$, the 8.9 -second edited strain signal of the rural strain signal experienced a decrease of fatigue damage by $8.3 \%$ and $8.9 \%$ for the Morrow and SWT models, respectively. However, the optimum EGV was $2,458 \mu \varepsilon^{2} / \mathrm{Hz}$. With the optimum EGV, a rural strain signal of 30 seconds was shortened by $70.6 \%$ with the fatigue damage retained was $8.4 \%$ and $9 \%$. This indicated that the extraction process retained the fatigue damage of at least $91 \%$. Quantitatively, the difference of fatigue damage was in the required level: $10 \%$ difference. The counted number of cycles was 
reduced from 2,993 cycles until failure in the initial strain signal to 866 cycles until failure in the mission strain signal. For an EGV of $2,513 \mu \varepsilon^{2} / \mathrm{Hz}$, the wavelet-based extraction resulted in an 8.5-second edited strain signal, which was $71.6 \%$ shorter than the initial strain signal. Unfortunately, the fatigue damage of the mission strain signal changed by $10.3 \%$ and $11 \%$. Since the fatigue damage given by the mission strain signal was reduced by more than $10 \%$, the EGV could not be used as the parameter since it changed the initial strain signal behavior.

Changes of signal length, number of cycles and fatigue damage show that the third extraction provided the highest changes, followed by the second and first extractions, respectively. It was due to the third extraction that the EGV applied was higher, and thus, more energy amplitudes were removed. As a result, the edited strain signals were shorter, and had a lower fatigue damage. Overall, the FDE technique was able to identify fragments having higher fatigue damage and removed non-damaging fragments with magnitudes less than the EGV based on their positions on the time axis in the initial strain signals to improve their fatigue life. According to the findings, the FDE technique effectively summarized the strain signals by up to more than $81.5 \%$ with less than $10 \%$ difference with respect to the fatigue damage to ascertain that the extractions did not significantly affect the initial behavior.

\section{Clustering Fragments}

A relationship pattern between the initial and edited strain signals could be identified using the clustering method. In addition, the clustering also aimed to ensure that higher amplitude fragments could be detected and extracted from the initial strain signals, and at the same time maintained fatigue damage. For this purpose, the required data were fragments drawn from the fatigue feature extraction. The extracted features were clustered in order to analyze the fragment behavior based on related findings. The clustering provided a base for strain signal scattering, enabling the observation of the strain signal behavior.

In Figure 16, the fragments were clustered based on energy and fatigue damage, in which both the parameters were accurately correlated. The coefficients of determination of 0.8147 and 0.831 were obtained for the Morrow and SWT models, respectively, for the highway strain signal. For the urban strain signal, the coefficients of determination were 0.8047 and 0.7643 . The rural strain signal gave the highest coefficients of determination, which were 0.8134 and 0.9036 , indicating a very good correlation. The clustering plot was produced based on the proportional relationships between the fatigue damage and its corresponding energy. The pattern indicated that the fatigue damage was generally translated into energy. Fragments with higher energy levels presented greater fatigue damage, while fragments with lower energy levels presented less fatigue damage. With the loss of energy, the fatigue damage decreased. This meant that the clustering graph, in fact, reflected the hypothesized correlation. Energy can be used as a reference for determining fatigue damage because it produces data scattering that contains certain data, as expected. Introducing the extraction and the clustering of fatigue features, fatigue life assessments can be more accurate because each fragment only contained one peak in overall. 


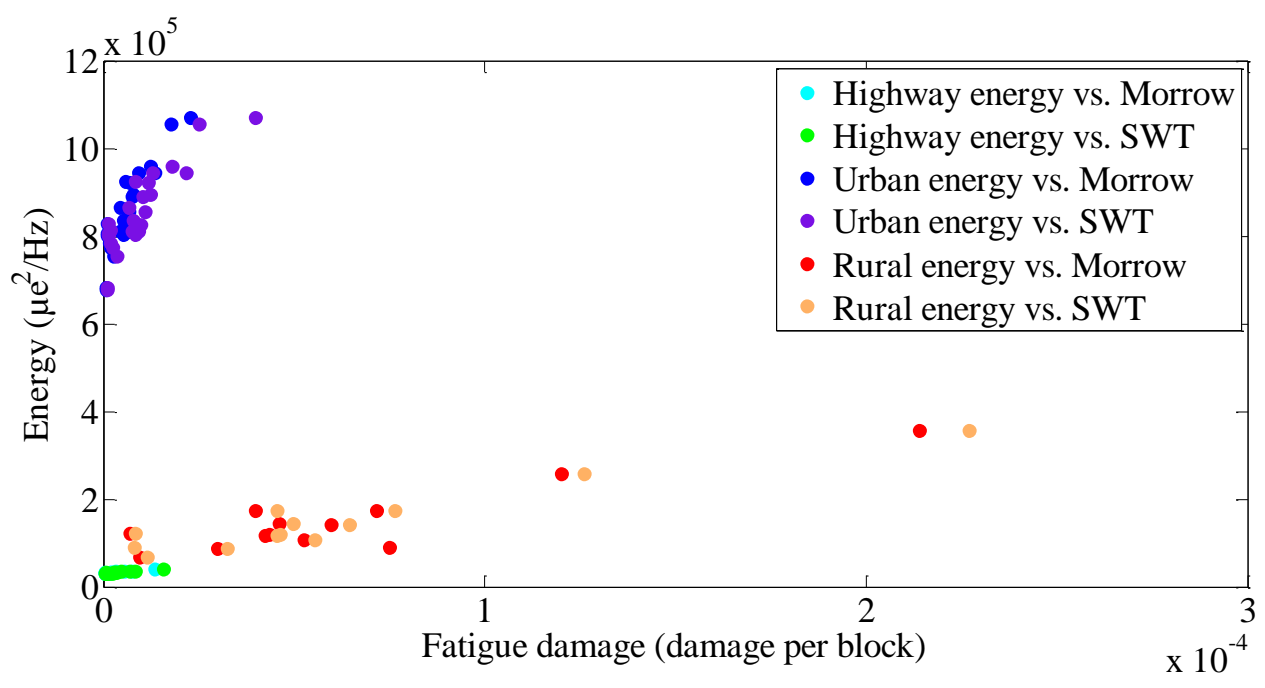

Figure 16. Fatigue feature clustering based on the wavelet energy and the fatigue damage.

\section{Fatigue Life}

In the case of subsequent validation process, the fatigue lives of the initial and the edited strain signals were experimentally estimated. The fatigue life increased in all the edited strain signals since the lower strain amplitudes that were eliminated in the extraction process actually contributed to minimum fatigue damage. When the minimum fatigue damage in the initial strain signals was removed, it provided additional lives for the edited strain signals before failure. The maximum increase was $3.6 \%$. The life, however, was not significantly different, which was below $10 \%$, showing the suitability of the FDE algorithm.

Though the edited strain signals resulted in a high fatigue life in comparison to the primary strain signals, a short fatigue testing time was obtained as a majority of the low amplitude fragments were eliminated. Testing time, however, is not necessarily proportional to strain amplitudes, since in a full-scale test small amplitudes usually have a shorter period (higher frequency) than large amplitudes. The primary strain signal of the highway road needed at least 2,840 reversals of blocks until failure in a time period of more than 7,100 minutes. After extraction, the strain signal length decreased up to $81.5 \%$ with 2,861 reversals of blocks, without any significant effect on the fatigue damage content. This resulted in a $81.4 \%$ decreased in the time needed for the fatigue test, i.e., 1,320 minutes.

The urban and rural roads showed similar conditions. The time required for performing the fatigue test for the initial urban strain signal was 1,055 minutes, with 422 reversals of blocks. The time was reduced by $2 \%$ using the 29.1 -second edited urban strain signal with 426 reversals of blocks. The rural strain signal gave the shortest testing time since it had the highest strain amplitudes. Only less than 138 minutes were required to conduct the fatigue tests utilizing the initial rural strain signal, with 55 reversals of blocks. The time could be reduced by $69.5 \%$ or only less than 42 minutes using the 8.8-second edited rural strain signal, involving 57 reversals of blocks.

There are requirements that should be considered when generating a new fatigue random load history, such as [3]: (1) sequence of load cycles should be maintained, (2) damage resulting from the new load history should be the same as the original load 
history, and (3) the new load history should be shorter in length than the original load history to decrease the testing time, by deleting small load cycles and merging smaller ones. Considering the requirements, the simulated strain signals were able to maintain the original cycle sequences, the actual and simulated strain signals had equivalent fatigue damage, and the simulated strain signals decreased the fatigue testing time. Laboratory experiments involving the acceleration of the durability testing were performed to clarify that although the fatigue tests took a shorter time than the initial strain signals, they had a similar potential for fatigue damage. The required testing time became shorter due to the use of a shorter strain signal.

\section{CONCLUSION}

This work discusses on the FDE technique validation using a clustering method. Based on the results, the FDE technique effectively shorten the strain signals by more than 81 $\%$ with less than $10 \%$ difference with respect to the fatigue damage to make sure that the technique did not significantly affect the initial behavior. Based on the clustering of the wavelet energy and the fatigue damage using the FCM, both the parameters were accurately correlated with the coefficient of determination up to 0.9036. Utilizing the edited strain signals, the fatigue testing time could be reduced up to $81.4 \%$. Without editing the service load before performing a fatigue test, the testing time and cost can become prohibitive. Thus, this method is suggested as an alternative technique in fatigue durability studies, especially in the field of automotive engineering.

\section{ACKNOWLEDGEMENT}

The authors would like to express their gratitude to Syiah Kuala University for financial support for this research through the grant No. 03/UN11.2/PP/PNBP/SP3/2017. The authors thank also to Department of Mechanical and Materials Engineering, Universiti Kebangsaan Malaysia, for providing facilities.

\section{REFERENCES}

[1] Scuracchio BG, de Lima NB, Schön CG. Role of residual stresses induced by double peening on fatigue durability of automotive leaf springs. Materials and Design 2013; 47: 672-676.

[2] Ko S-G, Oh C-S, Choi B-I. The elucidation of load history editing effect on fatigue crack growth by crack closure concept. International Journal of Fatigue 2005: 27: 255-262.

[3] Xiong JJ, Shenoi RA. A load history generation approach for full-scale accelerated fatigue tests. Engineering Fracture Mechanics 2008; 75: 3226-3243.

[4] Oh C-S. Application of Wavelet Transform in Fatigue History Editing. International Journal of Fatigue 2001; 23: 241-250.

[5] Abdullah S, Choi JC, Giacomin JA, Yates JR. Bump extraction algorithm for variable amplitude fatigue loading. International Journal of Fatigue 2006; 28: 675-691.

[6] Putra TE, Abdullah S, Schramm D, Nuawi MZ, Bruckmann T. Generating strain signals under consideration of road surface profiles. Mechanical Systems and Signal Processing 2015; 60-61: 485-497. 
[7] Putra TE, Abdullah S, Schramm D, Nuawi MZ, Bruckmann T. The need to generate realistic strain signals at an automotive coil spring for durability simulation leading to fatigue life assessment. Mechanical Systems and Signal Processing 2017; 94: 432-447.

[8] Prawoto Y, Ikeda M, Manville SK, Nishikawa A. Design and failure modes of automotive suspension springs. Engineering Failure Analysis 2008: 15: 11551174.

[9] nCode. ICE-flow 4.1: GlyphWorks worked examples. Sheffield: nCode International, Ltd.; 2007.

[10] Ilic, S. Methodology of evaluation of in-service load applied to the output shafts of automatic transmissions. Ph.D. Thesis, The University of New South Wales; 2006.

[11] Haiba M, Barton DC, Brooks PC, Levesley MC. The development of an optimisation algorithm based on fatigue life. International Journal of Fatigue 2003; 25: 299-310.

[12] dos Santos HAFA, Auricchio F, Conti M. Fatigue life assessment of cardiovascular balloon-expandable stents: a two-scale plasticity-damage model approach. Journal of the Mechanical Behavior of Biomedical Materials 2012; 15: 78-92.

[13] Nagode M. Continuous damage parameter calculation under thermo-mechanical random loading. MethodsX 2014; 1: 81-89.

[14] Ghafoori E, Motavalli M, Nussbaumer A, Herwig A, Prinz GS, Fontana M. Determination of minimum CFRP pre-stress levels for fatigue crack prevention in retrofitted metallic beams. Engineering Structures 2015; 84: 29-41.

[15] Nascimento MP, Voorwald HJC, Filho JCP. Fatigue strength of tungsten inert gas-repaired weld joints in airplane critical structures. Journal of Materials Processing Technology 2011; 211: 1126-1135.

[16] Schaumann P, Steppeler S. Fatigue tests of axially loaded butt welds up to very high cycles. Procedia Engineering 2013, 66: 88-97.

[17] Ye XW, Su YH, Han JP. A state-of-the-art review on fatigue life assessment of steel bridges. Mathematical Problems in Engineering 2014; 1-13.

[18] Callister WD, Rethwisch DG. Fundamentals of materials science and engineering: an integrated approach. $4^{\text {th }}$ ed. New Jersey: John Wiley \& Sons, Inc.; 2012.

[19] Klimkeit B, Nadot Y, Castagnet S, Nadot-Martin C, Dumas C, Bergamo S, Sonsino CM, Büter A. Multiaxial fatigue life assessment for reinforced polymers. International Journal of Fatigue 2011; 33: 766-780.

[20] Tao G, Xia Z. Mean stress / strain effect on fatigue behavior of an epoxy resin. International Journal of Fatigue 2007; 29: 2180-2190.

[21] Kovacs S, Beck T, Singheiser L. Influence of mean stresses on fatigue life and damage of a turbine blade steel in the VHCF-regime. International Journal of Fatigue 2013; 49: 90-99.

[22] Morrow J. Fatigue design handbook. Warrendale: Society of Automotive Engineers; 1968.

[23] Smith KN, Watson P, Topper TH. A stress-strain function for the fatigue of materials. Journal of Materials JMLSA 1970; 5: 767-778.

[24] Palmgren A. Die Lebensdauer von Kugellagern. Zeitschrift VDI 1924; 68: 339341. 
[25] Miner MA. Cumulative damage in fatigue. Journal of Applied Mechanics 1945; 67: A159-A164.

[26] Upadhyaya YS, Sridhara BK. Fatigue life prediction: a continuum damage mechanics and fracture mechanics approach. Materials and Design 2012; 35: 220-224.

[27] Kim BS, Lee SH, Lee MG, Ni J, Song JY, Lee CW. A comparative study on damage detection in speed-up and coast-down process of grinding spindle-typed rotor-bearing system. Journal of Materials Processing Technology 2007; 187188: 30-36.

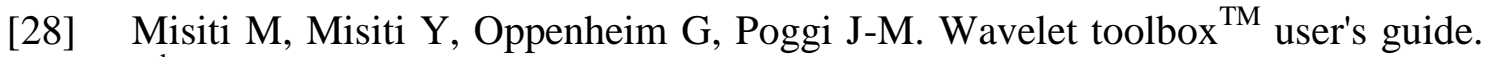
$4^{\text {th }}$ ed. MA: The Math Works, Inc.; 2008.

[29] Chen H, Zuo MJ, Wang X, Hoseini MR. An adaptive Morlet wavelet filter for time-of-fight estimation in ultrasonic damage assessment. Measurement 2010; 43: 570-585.

[30] Morlet J, Arens G, Fourgeau E, Giard D. Wave propagation and sampling theory - Part I: Complex signal and scattering in multilayered media. Geophysics 1982; 47: 203-221.

[31] Morlet J, Arens G, Fourgeau E, Giard D. Wave propagation and sampling theory - Part II: Sampling theory and complex waves. Geophysics 1982; 47: 222-236.

[32] Tang B, Liu W, Song T. Wind turbine fault diagnosis based on Morlet wavelet transformation and Wigner-Ville distribution. Renewable Energy 2010; 35: 2862-2866.

[33] Daubechies I. Ten lectures on wavelets. Philadelphia: Society for Industrial and Applied Mathematics; 1992.

[34] Mallat S. A Wavelet tour of signal processing. $3^{\text {rd }}$ ed. MA: Elsevier, Inc.; 2009.

[35] Darpe AK. A novel way to detect transverse surface crack in a rotating shaft. Journal of Sound and Vibration 2007; 305: 151-171.

[36] Abu-Mahfouz I, Banerjee A. Drill wear feature identification under varying cutting conditions using vibration and cutting force signals and data mining techniques. Procedia Computer Science 2014; 36: 556-563.

[37] Liao TW. Clustering of time series data - a survey. Pattern Recognition 2005; 38: $1857-1874$.

[38] Bezdek JC. Pattern recognition with Fuzzy objective function algorithms. New York: Plenum Press; 1981.

[39] Das S. Pattern recognition using the Fuzzy C-Means technique. International Journal of Energy, Information and Communications 2013; 4.

[40] Sonsino CM. Fatigue testing under variable amplitude loading. International Journal of Fatigue 2007; 29: 1080-1089.

[41] Aykan M, Çelik M. Vibration fatigue analysis and multi-axial effect in testing of aerospace structures. Mechanical Systems and Signal Processing 2009; 23: 897907.

[42] Carvalho ALM, Martin JP, Voorlwad HJC. Fatigue damage accumulation in aluminum 7050-T7451 alloy subjected to block programs loading under stepdown sequence. Procedia Engineering 2010; 2: 2037-2043.

[43] Niesłony A, Böhm M. Mean stress effect correction using constant stress ratio S-N curves. International Journal of Fatigue 2013; 52: 49-56.

[44] Rognin F, Abdi F, Kunc V, Lee M, Nikbin K. Probabilistic methods in predicting damage under multi-stage fatigue of composites using load block sequences. Procedia Engineering 2009; 1: 55-58. 
[45] ASTM E606-92. Standard practice for strain-controlled fatigue testing. West Conshohocken: ASTM International; 1998.

[46] ASTM E112-96. Standard test methods for determining average grain size. West Conshohocken: ASTM International, 2004.

[47] Ramberg W, Osgood WR. Description of stress-strain curves by three parameters. National Advisory Committee for Aeronautics 1943.

[48] Hosoi A, Takamura K, Sato N, Kawada H. Quantitative evaluation of fatigue damage growth in CFRP laminates that changes due to applied stress level. International Journal of Fatigue 2011; 33: 781-787. 